\title{
Lava discharge rates from satellite-measured heat flux
}

\author{
Andrew J. L. Harris ${ }^{1}$ and Stephen M. Baloga ${ }^{2}$ \\ Received 1 July 2009; revised 31 July 2009; accepted 10 August 2009; published 2 October 2009.
}

[1] A commonly used method to convert lava flow area to volume flux using low spatial resolution satellite data rests on two primary assumptions, that: (1) volume flux is related to flow area, and (2) lava surfaces cool exponentially with time and distance from the source. Field data show that both assumptions are valid. The ensuing relationship is an empirical one in which flow area is proportional to timeaveraged discharge rate under given compositional, insulation, rheological and ambient conditions. Thus, the proportionality has to be determined depending on flow conditions, and the conversion set and applied on a case-bycase basis. Citation: Harris, A. J. L., and S. M. Baloga (2009), Lava discharge rates from satellite-measured heat flux, Geophys. Res. Lett., 36, L19302, doi:10.1029/2009GL039717.

\section{Introduction}

[2] A relationship proposed by Pieri and Baloga [1986] is now widely used in remote sensing to convert active lava flow area to lava volume flux. The relationship was first presented as a method for estimating lava volume flux for planetary lava flows by Crisp and Baloga [1990], and was subsequently adapted by Harris et al. [1997] to convert satellite-derived heat fluxes for active terrestrial lava flows to volume fluxes. The method was further adapted and applied to various effusive scenarios (basaltic, silicic, 'a'a, pahoehoe, fountain-fed, channel-fed, tube-fed) in a series of papers reviewed by Harris et al. [2007], with Wright et al. [2001] focusing on the application of the method to low spatial resolution (1 km pixel) satellite thermal data. Wright et al. [2001] concluded that the method operates by multiplying active flow area by a constant, the value of which is "obtained from a crude approximation of the lava flow heat balance". Further, Wright et al. [2001] found that the method did not yield instantaneous effusion rates, but instead provided "a valid and useful way to estimate average effusion rates from measurements of flow area". This was iterated by Harris et al. [2007] who used the term "time-averaged discharge rate" (TADR) to describe the output. TADR considers volume fluxes averaged over given time periods, so that the term TADR was thus adopted to stress the time-averaged nature of the output. Current consideration of the method culminated by Dragoni and Tallarico's [2009] theoretically-based re-examination of the assumptions behind the original relationship of Pieri and Baloga [1986]. In spite of these treatments, the application of the conversion method when applied to satellite thermal data, and the necessary assumptions, remain a source of

\footnotetext{
${ }^{1}$ Laboratoire Magmas et Volcans, Université Blaise Pascal, ClermontFerrand, France.

${ }^{2}$ Proxemy Research, Laytonsville, Maryland, USA.
}

Copyright 2009 by the American Geophysical Union. 0094-8276/09/2009GL039717 debate and confusion. This is apparent from Dragoni and Tallarico [2009] who argue that the underling assumptions of the original Pieri and Baloga [1986] model are not consistent with its use as a method for deriving TADR from satellite thermal data. However, a full consideration of the actual intent of the original Pieri and Baloga [1986] work, as well as the satellite-based approach of Harris et al. [1997], reveals why certain assumptions were used and remain valid today as approximations of realistic flow behavior. Consideration of field data reveal that the two main assumptions on which the method is based, i.e., that (1) TADR is related to flow length, and (2) lava surfaces cool in an essentially exponential fashion are, in fact, valid. Thus, to clarify the application of the method to low spatial resolution satellite data it is necessary to provide a full examination of the two original studies, as well as an assessment of their underlying assumptions using field data. Such a consideration shows that we rely on an empirical relationship whereby flow area is proportional to TADR under given insulation, rheological and ambient conditions.

\section{Relationship of Pieri and Baloga [1986]}

[3] The intent of Pieri and Baloga [1986] was to examine the observed correlation between erupted lava volume flux $(Q)$ and lava flow plan area $(A)$ for basaltic Hawaiian flows. To explore this, Pieri and Baloga [1986] developed the relation (for an unmixed case):

$$
Q=\frac{\varepsilon \sigma T_{e}^{4}}{\rho c_{p}\left(T_{o}-T_{f}\right)} A(L)
$$

where $\varepsilon$ is emissivity, $\sigma$ is the Stefan-Boltzmann constant, $T_{e}$ is the effective radiation temperature of the flow surface, $\rho$ is flow density, $c_{p}$ is the lava specific heat capacity, $T_{o}$ is the eruption temperature and $T_{f}$ is the temperature at which forward motion ceases. Equation (1) is applicable to cooling-limited flow, whereby flow has reached the maximum possible distance from the vent $(L)$. This is determined by the point at which the flow core cools to a temperature $\left(T_{f}\right)$ at which further forward motion is rheologically impossible. This relation, as stressed by Pieri and Baloga [1986], was based on pioneering fluid dynamic treatments of lava flow emplacement dating back to Daneš [1972]. It is, indeed, based on a common heat loss problem in geology [see, e.g., Furbish, 1997] and has been applied, for example, to examine mass fluxes at lava lakes on the basis of the associated heat flux [Francis et al., 1993]. The intent of the Pieri and Baloga [1986] formulation was to recognize two shortcomings of earlier models [e.g., Daneš, 1972; Park and Iversen, 1984]. First, the radiative heat loss from the surface of an active flow cannot be adequately characterized by the vertically averaged temperature of a column within the flow. Field observation shows that flow 


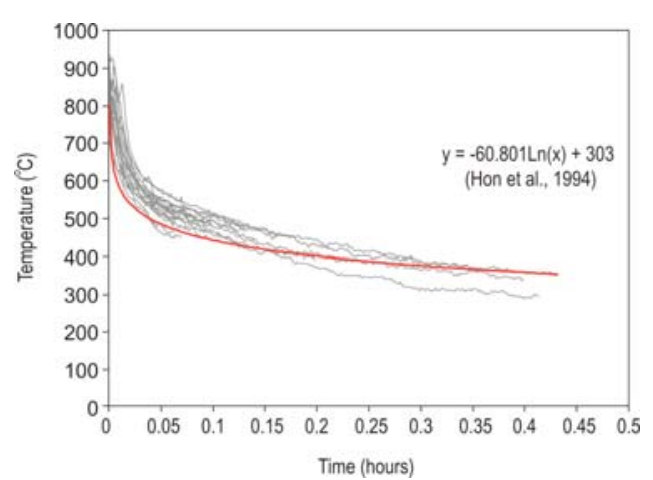

Figure 1. Cooling curves for surface crusts forming on pahoehoe lava flows at Kilauea obtained with a thermal infrared $(8-14 \mu \mathrm{m})$ thermometer (data are corrected for a $8-14 \mu \mathrm{m}$ emissivity for Hawaiian basalt of 0.95 ). Forty cooling curves are defined, each showing logarithmic decay ranging between $\mathrm{y}=-96.006 \ln (\mathrm{x})+281.04\left(\mathrm{R}^{2}=0.97\right)$ and $\mathrm{y}=-98.5 \ln (\mathrm{x})+189.17\left(\mathrm{R}^{2}=0.90\right)$. The cooling trend of Hon et al. [1994] is given for comparison.

surface temperature is typically less than that of the interior [e.g., Hon et al., 1994]. This is apparent in the field data given in Figure 1 where maximum surface temperatures are between $710^{\circ} \mathrm{C}$ and $1026^{\circ} \mathrm{C}\left(\right.$ mean $\left.=860^{\circ} \mathrm{C}, \sigma=70^{\circ} \mathrm{C}\right)$ and compare with a thermocouple-derived core temperature of $1164^{\circ} \mathrm{C}$. Consequently, a constant and representative surface temperature $\left(T_{e}\right)$ was proposed that could be derived by appropriate averaging over both space and time (see Text S1 of the auxiliary material). ${ }^{1}$ Second, flow area was introduced to allow sensitivity of ultimate flow length to upstream width variations. Such sensitivities are manifested in relatively low viscosity flows where flow dimensions are influenced by pre-existing topography along the flow path, as well as a number of other factors such as channel breaching, overflow and bifurcation [e.g., Kilburn and Lopes, 1988]. These sensitivities can mask the thermallyderived proportionality between volume flux and the maximum flow extent. For example, a flow with significant topographically induced widening near the vent would have a different radiative loss history from one that widens near the terminus, even though both were erupted under identical vent conditions. Thus, fundamental to the steady-state relation expressed by equation (1) is the assumption that flow plan area is related to the erupted lava volume flux through flow cooling. These, and other key assumptions, are debated by Dragoni and Tallarico [2009]. However, what Pieri and Baloga [1986] actually did was to explore the thermal conditions, i.e., combinations of $T_{e}$ and $\Delta T\left(=T_{o}-T_{f}\right)$, that allowed the $Q$ versus $A$ regressions found for Hawaiian flows to be replicated (see Text S1). In effect, an empirical relation was defined using the intrinsic compositional flow parameters $\left(\rho, c_{p}\right)$ as well as thermal insulation $\left(T_{e}\right)$ and cooling $(\Delta T)$ parameters.

\section{Full Method of Harris et al. [1997]}

[4] The formula of Pieri and Baloga [1986] was adapted by Harris et al. [1997] to allow satellite-derived spectral

\footnotetext{
${ }^{1}$ Auxiliary materials are available in the HTML. doi:10.1029/ 2009GL039717.
}

radiance for an active flow to be converted from units used by the remote sensing community, i.e., $\mathrm{mW} \mathrm{m} \mathrm{m}^{-2} \mathrm{sr}^{-2} \mu \mathrm{m}^{-1}$, to a value that is of more use to the volcanological community, i.e., volume flux in units of $\mathrm{m}^{3} \mathrm{~s}^{-1}$. The first, and most important, step in completing the conversion is to assess the area of active lava $(A)$ within the pixel. Although this important step is not considered by Dragoni and Tallarico [2009], a full consideration of these methodological steps is necessary if we are to understand the limits of the resulting conversion.

[5] Given the low spatial resolution of the data $(1 \mathrm{~km}$ Advanced Very High Resolution Radiometer [AVHRR] pixels) and the availability of just one waveband of data, a two component model had to be applied that considered the pixel to be filled by a mixture of active lava with a surface temperature of $T_{c}$ and ambient ground at $T_{a}$. Now, using the AVHRR band 4 (10.5 to $11.5 \mu \mathrm{m})$ pixel-integrated radiance $\left(R_{4}\right)$, the pixel portion occupied by active lava can be estimated from:

$$
R_{4}=p L_{4}\left(T_{c}\right)+(1-p) L_{4}\left(T_{a}\right)
$$

in which $L_{4}$ is the Planck Function for AVHRR band 4 and $p$ denotes the pixel portion occupied by a surface at $T_{\mathrm{c}}$. Multiplying $p$ by pixel area then gave the active lava area. Given an assessment of $T_{a}$ based on the temperature of surrounding, lava-free, pixels, an assumed value for the lava surface was necessary in order to solve for $p$. As argued by Harris et al. [1997], a crust-dominated scenario was assumed with higher temperature cracks being of a sufficiently small size so as to contribute negligible amounts of radiance in the 10.5 to $11.5 \mu \mathrm{m}$ waveband (see Text S1). A similar approach was published in the same year to estimate active lava areas in $1 \mathrm{~km}$ Along Track Scanning Radiometer data by Wooster and Rothery [1997]. The mixture model applied by Harris et al. [1997] meant that some reasonable temperature range had to be assumed for the flow surface. It was recognized that surface temperatures of active lavas were highly variable, varying from near magmatic temperatures over channels near the vent to much lower temperatures at mature, heavily crusted, surfaces near the flow front. However, the limits imposed by use of $1 \mathrm{~km}$ data and a single waveband of data meant that a complex model that varied temperature in space was impossible to apply. However, to assume a single temperature was dramatically at odds with field experience (see Text S1). As a result, Harris et al. [1997] opted for solution over a range of surface temperatures from $100^{\circ} \mathrm{C}$ to $500^{\circ} \mathrm{C}$, which respectively gave a maximum and minimum bound for the pixel portion occupied by active lava and, hence, lava flow area. As shown in Text S1, the assumed crust-dominated scenario, and assumed surface temperature range, is consistent with available field data for basaltic lava flows. The upper bound needs to be increased to $1000^{\circ} \mathrm{C}$ in cases where long lengths of poorly crusted channel are active, as was the case for Etna's fountain fed flows of November 1999. Hence, Harris and Neri [2002] in their analysis of AVHRR data for the same flows assumed a range of $100^{\circ} \mathrm{C}$ to $1000^{\circ} \mathrm{C}$ when applying the equation (2) mixture model. It is important to understand these temperature limits, because their adoption now controls the conversion to volume flux. Using these characteristic surface temperature envelopes, 
the Harris et al. [1997] mixture model gives a range of derived flow areas and heat fluxes. These are used in equation (1) to convert to volume flux. At this point Dragoni and Tallarico [2009] pick up the method. Of course, as pointed out by Dragoni and Tallarico [2009], inputting a range of flow areas produces a wide range of volume fluxes. However, given the absence of field measurements simultaneous with the satellite overpass and uncertainty in the assumed values, attempting to make the range smaller would have added a misleading air of precision to the results, which are, in fact, comparable to the range of uncertainties in fieldbased measurements [Harris et al., 2007].

[6] Wright et al. [2001] point out two important assumptions made as part of this method, the second of which needs to be added to the assumption list of Dragoni and Tallarico [2009]. First, the approach assumes a linear correlation between erupted volume flux and lava flow area. Wright et al. [2001] pointed out that, if we consider the values input into the method, area becomes the only variable so that the relation reduces to $Q=x A$ (see Text $\mathrm{S} 1$ ). Thus, we move towards a situation similar to the approach of Pieri and Baloga [1986] whereby characteristic compositional and thermal properties of the lava are used to calibrate a proportionality between $Q$ and $A$. In fact, working backwards through the calculation steps shows that the only variable becomes the initial measurement, at-sensor spectral radiance $(R)$, meaning that we can also use $Q=x R$, as done by Harris and Ripepe [2007]. Secondly, Wright et al. [2001] point out that a strictly defined effusion rate is not an appropriate term for the parameter used in this relationship. Instead a time-averaged volume flux value is appropriate. Wright et al. [2001] argue that the area of an active flow is not reflective of the instantaneous at-vent volume flux or effusion rate. Rather it is reflective of the antecedent volume flux, integrated over some period prior to satellite overpass. For example, if a satellite measurement is made at 12:00, one "effusion rate" is generated. If effusion triples at 12:01, and another satellite measurement is made at 12:02, the new calculated effusion rate will not be three times higher because it takes time for the higher effusion rate to propagate downstream and cause perceptible increases in flow area. However, after sufficient time, the new elevated effusion rate will result in an increase in flow area. Thus, to stress this point, Harris et al. [2007] used the term timeaveraged discharge rates to describe the output of the model and to highlight the fact that we were considering volume fluxes averaged over a given time period. In terms of the Pieri and Baloga [1986] relationship, TADR is the volume flux averaged over the time it takes to emplace the coolinglimited unit of length $L$.

\section{Assumptions}

[7] Dragoni and Tallarico [2009] took issue with two assumptions in the above formulations. First, Dragoni and Tallarico [2009] objected to the notion that $Q$ is proportional to $L$ stating that this was "absurd" and that the assumption that "effusion rate is an increasing function of flow length" was "unrealistic". Second, Dragoni and Tallarico [2009] point out that "the most questionable assumption is probably the constancy of the crust temperature" and that "realistically, crust temperature should vary with distance". Although the validity of these two important assumptions has not been adequately assessed to date, field data show them to be valid.

\subsection{Relationship Between TADR and Lava Flow Length and Area}

[8] George Walker was one of the first workers to indicate that TADR $(Q)$ was proportional to lava flow length [Walker, 1973]. Walker [1973] plotted (for 41 flows of three different compositions at 19 different volcanoes) $Q$ versus $L$ and noted "although there is a scatter of points, it is striking how good is the correlation between length of flow when one bears in mind that the data are drawn from different volcanoes" [Walker, 1973]. Such a relationship has also been found for single volcanoes, where Wadge [1978] and Calvari and Pinkerton [1998] report proportionality between $Q$ and $L$ for lava units measured at Etna. Lava flow length must in some sense be proportional to $Q$, as it is implicit in its definition for a given flow (see Text S1). Only the numerical value of the proportionality can be at issue, and whether a set of flows are erupted under sufficiently similar conditions to evaluate the proportionality. Assuming that degassing and vesiculation are negligible influences on the conservation of lava volume during emplacement, formulation of a thermal balance between the heat within the erupted flow volume and that lost from it must fundamentally relate $Q$ to $L$. More specifically, $Q$ must relate to the time-dependent changes in the plan area of the flow (see Text S1). If we follow up on the work of Kilburn and Lopes [1988] we can express TADR in terms of lava flow unit width $(W)$, length $(L)$, thickness $(H)$ and emplacement time $(\Sigma t)$,

$$
T A D R=(n W L H) / \Sigma t
$$

$n$ being a shape factor. Thus TADR is related to flow length, width, thickness and emplacement time. As a result, Pieri and Baloga [1986] took the analysis a step further by considering the relationship between TADR and flow area(= $n W L)$. Pieri and Baloga [1986] concluded that TADR "is correlated with the total length of the flow only in the sense that this length is a surrogate measurement of the plan area of the flow". However, we need to stress another very important caveat: a $Q$ versus $A$ relationship will only hold for the specific thermal, rheological, compositional and ambient (e.g., slope and flow bed roughness) conditions for which it has been derived. We note that the relationship will become blurred if different populations (defined by differing insulation, rheological and slope conditions) become mixed. This was the point of Pinkerton and Wilson [1994] who analyzed the fact, pointed out by Malin [1980], that Walker's [1973] relation between $Q$ and $L$ did not hold if data for Hawaiian flows were considered. Pinkerton and Wilson [1994] showed that if tube-fed flows were omitted from the data set then the relation did, in fact, hold. Simply, at a given $Q$, well-insulated (tube-contained) flow will extend a greater distance than poorly-insulated (channelfed) flow. Hence, the two populations (well-insulated and poorly-insulated Hawaiian flows) have to be considered separately. Likewise the relationship will vary between different rheological regimes and slope conditions. Thus a relationship developed for Hawaii cannot be applied to Etna, and a relationship derived for high slopes cannot be 
applied to low slopes. As a result, for example, Calvari and Pinkerton's [1998] relationship between $Q$ and $L$ for Etnean flows improved if slope was included.

\subsection{Constancy of Crust Temperature}

[9] Crust temperature decreases with distance from the vent as it ages and cools. However, both the limits of the satellite data and the simplicity of the initial formulation require choice of a characteristic (single) temperature for the flow surface. The assumption of a constant surface temperature can hold if heat flux is independent of flow length. This condition, in turn, "can be approximated if the crust temperature decreases (say exponentially) with distance" [Dragoni and Tallarico, 2009], so that $T_{c}$ must decline with distance, $x$, following [Dragoni and Tallarico, 2009]:

$$
T_{c}(x)=T_{c} \exp ^{\left(-x / x_{0}\right)} \mathrm{x} \geq 0
$$

$\mathrm{x}_{0}$ being the characteristic length for the temperature decrease. Field measurements for the temperature of cooling crusts on Hawaiian pahoehoe lava flows have shown that this is indeed the case. Hon et al. [1994] showed that, once surface temperature drops below $1070^{\circ} \mathrm{C}$, a crust forms and begins to cool. Measurement of surface temperature $\left(T_{\text {sur }}\right.$, in ${ }^{\circ} \mathrm{C}$ ) through time ( $t$, in hours) showed that surface cooling could be expressed empirically by:

$$
T_{\text {surf }}=-140 \log (t)+303
$$

As shown here in Figure 1 the trend is easily replicated and results from cooling by conduction across the surface crust [Hon et al., 1994]. This varies with $\sqrt{ } t$ so that surface cooling follows a predictable trend. We can thus expect a stable surface crust to cool in such a manner with distance from the vent, as seen in data for 'a'a flows. Here, Oppenheimer [1991] recorded a logarithmic decline in surface temperature with distance $(x$, in $\mathrm{m})$ from the vent at Lonquimay's 1989 'a'a flow:

$$
T_{\text {surf }}=218-\ln (x)
$$

This is consistent with down-flow profiles of surface temperature obtained for Sierra Negra's 1979 flow [Rothery et al., 1988], Etna's 2001 flow [Lombardo et al., 2009], and silicic lava flows at Santiaguito [Harris et al., 2004], where each profile is characterized by rapid, near-source, surface cooling and a dominant zone of cooler, stable, temperatures across most of the flow.

\section{Discussion}

[10] We arrive at a point whereby surface temperature needs to be set according to flow emplacement conditions, with the $Q$ versus $A$ relationship being set accordingly. To do this, surface thermal conditions and core cooling conditions are varied through manipulation of $\mathrm{T}_{\mathrm{e}}$ and $\Delta T$, respectively (see Text S1). However, Dragoni and Tallarico [2009] conclude that "apparently reasonable results were found since a weakness of the model, assuming a uniform, crust temperature, is compensated for by inconsistent use of the formulae." As argued above, the temperature assumption is a necessary one. Given that equation (4) holds, it is also a broadly realistic one. Inconsistent use of the formulae claimed by Dragoni and Tallarico [2009] appears to be a misinterpretation of the application. What we have is an empirical relation between flow area and discharge rate which varies from case to case depending on differences in insulation, rheology, slope, and a host of other disparate factors such as crystallinity, bed roughness, transient eruption conditions, etc. A relationship derived for tube-fed basaltic pahoheoe on a flat surface, for example, will not apply to channel-fed basaltic 'a'a flow on a steep slope. Likewise, a relation derived for a silicic flow at Santiaguito will not apply to a basaltic flow on Etna. Thus, as was the spirit of Pieri and Baloga [1986], we must vary the surface thermal state $\left(\mathrm{T}_{\mathrm{e}}\right)$ and internal cooling conditions $(\Delta T)$ from case to case to obtain a linear best fit between $Q$ and $A$. The resulting proportionality must then only be applied to lava flows and eruptions within the same broad population of possibilities. The point is, $\mathrm{T}_{\mathrm{e}}$ and $\Delta T$ need to be set according to the known eruption temperature and rheological regime, so that $\mathrm{T}_{\mathrm{e}}$ and $\Delta T$, as well as $\varepsilon, \rho$ and $\mathrm{C}_{\mathrm{p}}$, are case dependent and help set the proportionality between $Q$ and $A$ for each case. To test whether we have the relation right or not we can compare model output TADR with field measured values. In cases where field-measurements are available near-simultaneous with the satellite overpass, the two values are in good agreement [see Harris et al., 2007, Figure 10]. Thus, we appear to have correctly set the relation for each case thus far considered. This was most recently shown by Vicari et al. [2009] who, in applying the methodology of Harris et al. [1997] with the best fit parameters for Etna to low spatial resolution satellite thermal data for Etna's 2006 eruption, obtained TADR's which were in excellent agreement with ground-based estimates.

\section{Conclusion}

[11] The limits of low spatial resolution satellite data allow nothing more than the assumption of a range of characteristic lava flow surface temperatures to describe the likely, flow-wide, thermal state of the flow surface. To convert such simple, flow-averaged numbers to a timeaveraged discharge rate requires an equally simple model that averages emplacement conditions in space and time. While such a model needs to be solvable, measureable and testable within the limits of available data, it also needs to be based on realistic assumptions regarding lava flow properties averaged in space and time. This model was given by Pieri and Baloga [1986] and allows us to set cooling-limited lava flow area proportional to time-averaged discharge rate. As argued by Wright et al. [2001], the model reduces to an empirical relationship in which $Q$ is proportional to $A$. The proportionality varies by case depending on variations in thermal insulation, rheology and underlying slope. As shown by Harris et al. [2007], if set and applied correctly, the relationship provides $Q$ that are similar to field-based measurements and span a similar range of uncertainty. This, to paraphrase Dragoni and Tallarico [2009], explains the apparent success of the model.

[12] Acknowledgments. We are indebted to Robert Wright for insightful email discussions that contributed to arguments presented here, and to reviews by Letizia Spampinato and Matthew Patrick. 


\section{References}

Calvari, S., and H. Pinkerton (1998), Formation of lava tubes and extensive flow field during the 1991-1993 eruption of Mount Etna, J. Geophys. Res., 103(B11), 27,291-27,301, doi:10.1029/97JB03388.

Crisp, J., and S. Baloga (1990), A method for estimating eruption rates of planetary lava flows, Icarus, 85(2), 512-515, doi:10.1016/00191035(90)90129-W.

Daneš, Z. (1972), Dynamics of lava flows, J. Geophys. Res., 77(8), 1430-1432, doi:10.1029/JB077i008p01430.

Dragoni, M., and A. Tallarico (2009), Assumptions in the evaluation of lava effusion rates from heat radiation, Geophys. Res. Lett., 36, L08302, doi:10.1029/2009GL037411.

Francis, P., C. Oppenheimer, and D. Stevenson (1993), Endogenous growth of persistently active volcanoes, Nature, 366, 554-557, doi:10.1038/366554a0.

Furbish, D. J. (1997), Fluid Physics in Geology, 476 pp., Oxford Univ. Press, New York.

Harris, A. J. L., and M. Neri (2002), Volumetric observations during paroxysmal eruptions at Mount Etna: Pressurized drainage of a shallow chamber or pulsed supply?, J. Volcanol. Geotherm. Res., 116, 79-95, doi:10.1016/S0377-0273(02)00212-3.

Harris, A. J. L., and M. Ripepe (2007), Regional earthquake as a trigger for enhanced volcanic activity: Evidence from MODIS thermal data, Geophys. Res. Lett., 34, L02304, doi:10.1029/2006GL028251.

Harris, A. J. L., S. Blake, D. A. Rothery, and N. F. Stevens (1997), A chronology of the 1991 to 1993 Etna eruption using AVHRR data: Implications for real time thermal volcano monitoring, J. Geophys. Res., 102(B4), 7985-8003, doi:10.1029/96JB03388.

Harris, A. J. L., L. P. Flynn, O. Matias, W. I. Rose, and J. Cornejo (2004), The evolution of an active silicic lava flow field: An ETM+ perspective, J. Volcanol. Geotherm. Res., 135, 147-168, doi:10.1016/j.jvolgeores. 2003.12.011.

Harris, A. J. L., J. Dehn, and S. Calvari (2007), Lava effusion rate definition and measurement: A review, Bull. Volcanol., 70, 1-22, doi:10.1007/ s00445-007-0120-y.

Hon, K., J. Kauahikaua, R. Denlinger, and K. Mackay (1994), Emplacement and inflation of pahoehoe sheet flows: Observations and measurements of active lava flows on Kilauea Volcano, Hawaii, Geol. Soc. Am. Bull., 106, 351-370, doi:10.1130/0016-7606(1994)106<0351: EAIOPS $>2.3 . \mathrm{CO} ; 2$.

Kilburn, C. R. J., and R. M. C. Lopes (1988), The growth of aa lava fields on Mount Etna, Sicily, J. Geophys. Res., 93, 14,759-14,772, doi:10.1029/JB093iB12p14759.
Lombardo, V., A. J. L. Harris, S. Calvari, and M. F. Buongiorno (2009), Spatial variations in lava flow field thermal structure and effusion rate derived from very high spatial resolution hyperspectral (MIVIS) data, J. Geophys. Res., 114, B02208, doi:10.1029/2008JB005648.

Malin, M. C. (1980), Lengths of Hawaiian lava flows, Geology, 8 , 306-308, doi:10.1130/0091-7613(1980)8<306:LOHLF>2.0.CO;2.

Oppenheimer, C. (1991), Lava flow cooling estimated from Landsat Thematic Mapper infrared data: The Lonquimay eruption (Chile, 1989), J. Geophys. Res., 96, 21,865-21,878, doi:10.1029/91JB01902. Park, S., and J. D. Iversen (1984), Dynamics of lava flow: Thickness growth characteristics of steady two-dimensional flow, Geophys. Res. Lett., 11(7), 641-644, doi:10.1029/GL011i007p00641.

Pieri, D. C., and S. M. Baloga (1986), Eruption rate, area, and length relationships for some Hawaiian lava flows, J. Volcanol. Geotherm. Res., 30, 29-45, doi:10.1016/0377-0273(86)90066-1.

Pinkerton, H., and L. Wilson (1994), Factors effecting the lengths of channel-fed lava flows, Bull. Volcanol., 56, 108-120.

Rothery, D. A., P. W. Francis, and C. A. Wood (1988), Volcano monitoring using short wavelength infrared data from satellite, J. Geophys. Res., 93(B7), 7993-8008, doi:10.1029/JB093iB07p07993.

Vicari, A., A. Ciruado, C. Del Negro, A. Herault, and L. Fortuna (2009), Lava flow simulations using discharge rates from thermal infrared satellite imagery during the 2006 Etna eruption, Nat. Hazards, 50, 539-550, doi:10.1007/s11069-008-9306-7.

Wadge, G. (1978), Effusion rate and the shape of aa lava flow-fields on Mount Etna, Geology, 6, 503-506, doi:10.1130/0091-7613(1978)6<503: ERATSO $>2.0 . \mathrm{CO} ; 2$.

Walker, G. P. L. (1973), Lengths of lava flows, Philos. Trans. R. Soc. London, 274, 107-118, doi:10.1098/rsta.1973.0030.

Wooster, M. J., and D. A. Rothery (1997), Time-series analysis of effusive volcanic activity using the ERS along track scanning radiometer: The 1995 eruption of Fernandina volcano, Galapagos Islands, Remote Sens. Environ., 62, 109-117, doi:10.1016/S0034-4257(97)00087-4.

Wright, R., S. Blake, A. Harris, and D. Rothery (2001), A simple explanation for the space-based calculation of lava eruptions rates, Earth Planet. Sci. Lett., 192, 223-233, doi:10.1016/S0012-821X(01)00443-5.

S. M. Baloga, Proxemy Research, 20528 Farcroft Lane, Laytonsville, MD 20882, USA

A. J. L. Harris, Laboratoire Magmas et Volcans, Université Blaise Pascal, 5 Rue Kessler, F-63038 Clermont-Ferrand CEDEX, France. (a.harris@opgc. univ-bpclermont.fr) 